\title{
Clinical Usefulness of Aripiprazole and Lamotrigine in Schizoaffective Presentation of Tuberous Sclerosis
}

\author{
Seung-Yup Lee ${ }^{1}$, Jung-Ah Min $^{2}$, In Goo Lee ${ }^{3}$, Jung Jin Kim² \\ 'Department of Psychiatry, Uijeongbu St. Mary's Hospital, Uijeongbu, Departments of ${ }^{2}$ Psychiatry and ${ }^{3}$ Pediatrics, Seoul St. Mary's Hospital, \\ Seoul, College of Medicine, The Catholic University of Korea, Korea
}

\begin{abstract}
Tuberous sclerosis is not as rare as once thought and has high psychiatric comorbidities. However, bipolar or psychotic features associated with tuberous sclerosis have been rarely reported. This report first presents a tuberous sclerosis patient, resembling a schizoaffective disorder of bipolar type. A patient with known tuberous sclerosis displayed mood fluctuation and psychotic features. Her symptoms did not remit along with several psychiatric medications. After hospitalization, the patient responded well with lamotrigine and aripiprazole without exacerbation. As demonstrated in this case, tuberous sclerosis may also encompass bipolar affective or psychotic features. We would like to point out the necessity to consider bipolarity in evaluating and treating tuberous sclerosis.
\end{abstract}

KEY WORDS: Aripiprazole; Lamotrigine; Schizoaffective disorder; Tuberous sclerosis.

\section{INTRODUCTION}

Tuberous sclerosis (TSC) can involve almost every organ systems with symptom triads of mental retardation (MR), seizure and facial angiofibroma. It was previously assumed as a rare genetic disorder, ${ }^{1)}$ but the incidence of TSC at birth is now reported 1 in $6,000 .{ }^{2)} \mathrm{TSC}$ is an autosomal dominant disorder involving mutations in TSC1/ TSC2 genes, but two-thirds of TSC occur sporadically. ${ }^{3)}$ This implies that a patient without a known familial history of TSC could be affected by this hereditary disease and warrants clinical attention not limited to certain pedigrees.

For psychiatric comorbidities of TSC, attention deficit hyperactivity disorder (ADHD; 30-50\%) and autism (30-50\%) were reported frequent. ${ }^{4-7)}$ Depression, anxiety, MR and aggressive behavior were also common. ${ }^{7-9)}$ In contrast, manic or psychotic features in TSC have only been described in a number of case reports.

To the best of our knowledge, we present the first case

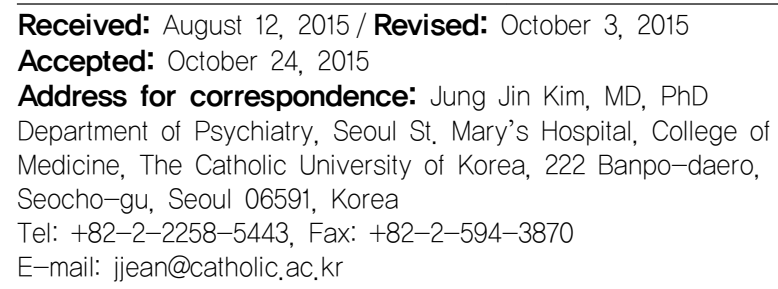

of a patient with TSC, resembling a schizoaffective disorder of bipolar type. After delineating and analyzing the case, review of relevant literature would be provided. The therapeutic utility of aripiprazole and lamotrigine will also be discussed as management options in TSC.

\section{CASE}

The patient was a 19-years-old female with a diagnosis of sporadic TSC made at the age of three after having multiple infantile spasms. She was on vigabatrin $1,500 \mathrm{mg}$ for her recurrent myoclonic seizures (2-3 times/month) throughout her childhood. Her medical records stated intermittent auditory hallucinations during that period. At the age of 13 years, the patient stopped her antiepileptic against medical recommendation. Following a seizure relapse at the age of 16 years, her electroencephalogram (EEG) revealed relatively frequent left occipital spikes. Topiramate $200 \mathrm{mg}$ was started, but she again discontinued it arbitrarily after five months.

Facial angiofibromas developed at the age of 11 years. Although her facial skin lesions became barely noticeable after multiple chemical skin peelings and laser therapies, she was continuously distressed with her appearance. To treat her depressed mood and social withdrawal, the patient received sertraline $50 \mathrm{mg}$ and pimozide $1 \mathrm{mg}$ at a private practice. Viewing that she was not fully responsive to 
the treatment, she visited our psychiatric outpatient department at Seoul St. Mary's Hospital, Catholic University of Korea.

A brain magnetic resonance imaging, ordered at her first visit, showed multiple non-enhancing cortical tubers and calcifications in both lateral ventricles suggesting subependymal nodules (Fig. 1). The intelligence test revealed borderline intellectual functioning (full-scale intelligence quotient [IQ], 77; verbal IQ, 83; performance IQ, 73).

Diagnosed with psychotic depression, venlafaxine 75 $\mathrm{mg}$ and risperidone $1 \mathrm{mg}$ were started. After one month, risperidone was discontinued and venlafaxine was increased to $150 \mathrm{mg}$ as the mood improved. Due to hypomanic features emerged at month 3, venlafaxine was discontinued and valproate $300 \mathrm{mg}$ was added. She displayed somewhat mixed features in mood with 2 months of fur- ther treatment. Eventually, loss of follow up occurred before she was hospitalized by her parents. The parents reported hallucinatory behaviors like silly smile and selftalking and their main complaints were irritability and neglect of self-care. The patient's refusal for foods prepared by her mother hinted presence of possible paranoid delusions.

In contrast, the chief complaint of the patient was depressed mood. Her thought process was relatively relevant and coherent. The thought contents were dissatisfaction and preoccupation with her appearance, and feelings of worthlessness. Persecutory delusions and delusions of reference were also displayed. Any forms of hallucinations were denied despite the reported history of hallucinatory behaviors.

While no other laboratory tests showed abnormality, the urine pregnancy test at the admission was tested posi-
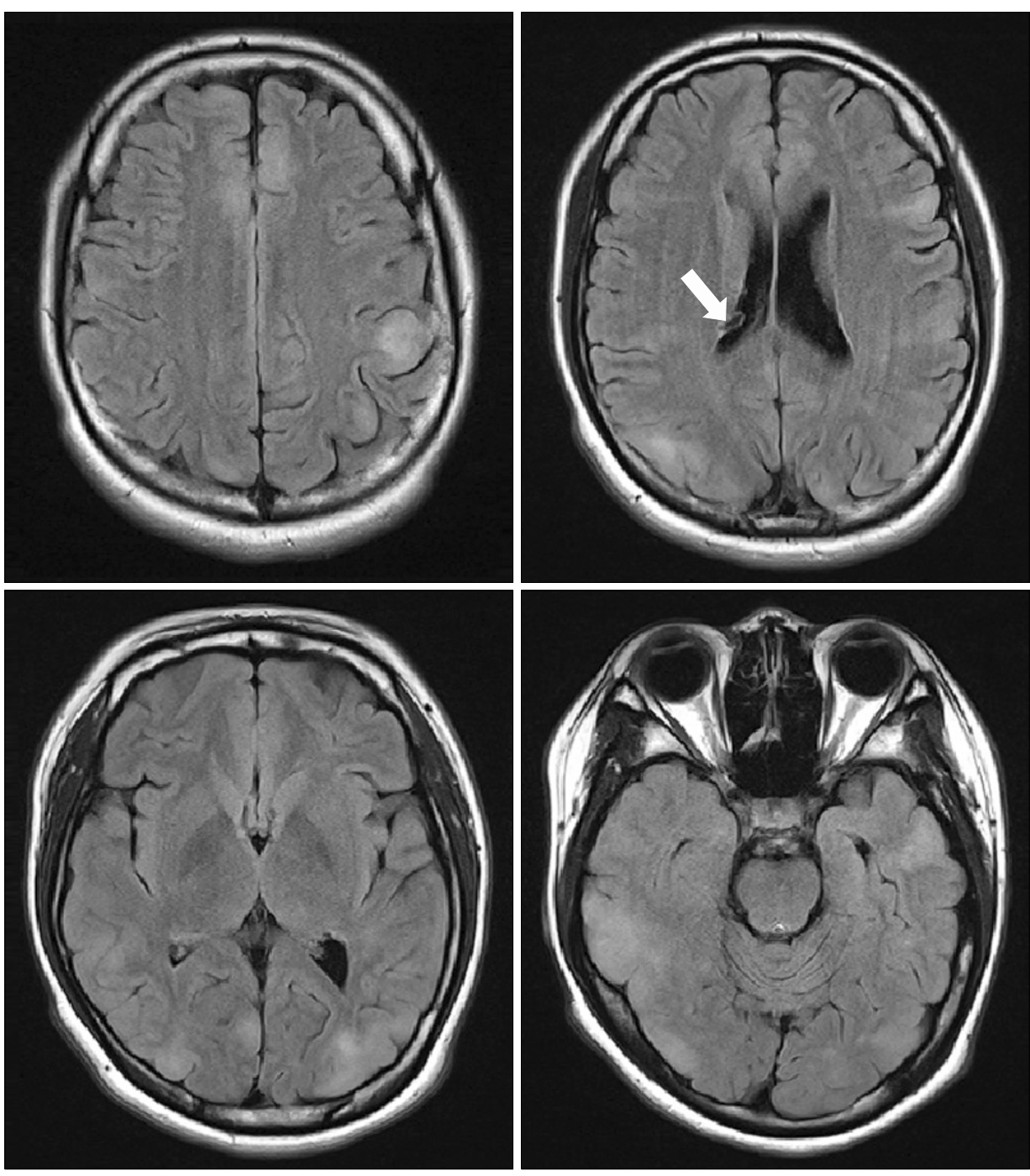

Fig. 1. Brain magnetic resonance imaging (T2- fluid attenuated inversion recovery) showing multiple cortical tubers and subependymal nodule (arrow). 
tive. After obstetric consultation, the false-positivity of the initial screening was confirmed. During the 5 days of drug-free period in ruling out pregnancy, worsening of manic symptoms occurred with the emergence of talkativeness and flight of ideas.

As pregnancy was ruled out, aripiprazole $5 \mathrm{mg}$ and valproate $600 \mathrm{mg}$ were started. While increasing aripiprazole and valproate doses to $15 \mathrm{mg}$ and $800 \mathrm{mg}$ respectively, she began to complain akathisia. Propranolol was added for akathisia control. After one week of inpatient treatment, the manic symptoms improved but psychomotor retardation worsened and sudden weight gain of $3 \mathrm{~kg}$ occurred. To alleviate the aforementioned side effects, valproate was switched to lamotrigine. An EEG performed at the time of the switch showed no epileptiform discharges.

However, the manic symptoms worsened again after 2 days of valproate discontinuation. Due to her aggravated hostility, regular visit by family members had to be stopped. The patient also admitted auditory hallucinations of criticizing nature. Aripiprazole was increased to $20 \mathrm{mg}$. Subsequently, the patient's mood and auditory hallucination were improved, but the persecutory delusions persisted. While increasing lamotrigine as scheduled, aripiprazole was increased to $30 \mathrm{mg}$ (Table 1).

During the admission, the patient repeatedly displayed negative perception of herself and others. Altogether with inefficient social skills, they were evaluated as contributing factors to her mood symptoms and paranoia. Therefore, brief cognitive therapy was carried out to improve the distorted self-images in addition to pharmacotherapy. Consequently, the patient's interactions with her family improved. After two successful overnight stay trials at home, she was finally discharged on 50th hospital day. The patient is now being followed up in the outpatients department for over 4 years without exacerbation, currently maintaining aripiprazole $15 \mathrm{mg}$ and lamotrigine $200 \mathrm{mg}$.

The institutional review board of the hospital approved this report after reviewing that no identifiable personal data were used and checking the presence of consent. Written informed consent was obtained both from the patient and her father for case report (IRB No. KC10EGSI0293).

\section{DISCUSSION}

Despite the high psychiatric comorbidities, psychotic or bipolar features of TSC are little known. Hence, it should be considered whether the symptoms are really caused by TSC. As such symptoms could also be caused by a pre-existing mood disorder, secondarily by a seizure disorder, or by antidepressants. However, we concluded that TSC itself directly caused the schizoaffective symptoms for the following reasons.

First of all, no temporal relationship exists to support depression as a cause for the psychotic state. Auditory hallucinations were stated on her medical record many years before the development of facial angiofibromas or depression. As the psychotic symptoms preceded her psychosocial stressor or depression, they can be hardly explained by a pre-existing mood disorder. In addition, the negative familial history of psychiatric illness and the extensive involvement of cortical tubers in the patient's brain all lessened the possibility of primary psychiatric disorder.

Secondly, the chance of a psychiatric disorder secon-

Table 1. Summary of clinical course and medications during hospitalization

\begin{tabular}{|c|c|c|}
\hline Timeline & Clinical course & Medications \\
\hline Admission day & Urine pregnancy test $(+)$ & Medications were held until false positivity later confirmed \\
\hline$\sim 5$ Hospital day & Hypomanic symptoms & ARP 5 mg, VPR 500 mg, LZP 0.5 mg \\
\hline$\sim 8$ Hospital day & Akathisia & PPL $20 \mathrm{mg}$ added \\
\hline$\sim 10$ Hospital day & $\begin{array}{l}\text { Side effects: Psychomotor retardation, Sudden } \\
\text { weight gain ( } 53 \mathrm{~kg} \text { to } 56 \mathrm{~kg} \text { ) }\end{array}$ & $\begin{array}{l}\text { VPR switched to LTG } \\
\text { ARP } 15 \mathrm{mg}, \text { LZP } 0.5 \mathrm{mg}, \text { PPL } 40 \mathrm{mg}, \text { BZT } 0.5 \mathrm{mg}\end{array}$ \\
\hline 13 Hospital day & $\begin{array}{l}\text { Hypomanic symptoms remerged with } \\
\text { increased irritability; } \\
\text { Complaint of auditory hallucination }\end{array}$ & ARP $20 \mathrm{mg}$, LTG $25 \mathrm{mg}$, LZP $1 \mathrm{mg}$, PPL $80 \mathrm{mg}$, BZT $0.5 \mathrm{mg}$ \\
\hline 21 Hospital day & $\begin{array}{l}\text { Mood stabilized but persistent } \\
\text { psychotic symptoms }\end{array}$ & ARP $30 \mathrm{mg}$, LTG $25 \mathrm{mg}$, LZP $1 \mathrm{mg}$, PPL $80 \mathrm{mg}$, BZT $0.5 \mathrm{mg}$ \\
\hline 30 Hospital day & $\begin{array}{l}\text { Auditory hallucination : improved } \\
\text { Paranoid ideation: remained }\end{array}$ & ARP $30 \mathrm{mg}$, LTG $50 \mathrm{mg}$, LZP $1 \mathrm{mg}$, PPL $80 \mathrm{mg}$, BZT $0.5 \mathrm{mg}$ \\
\hline 50 Hospital day & Interpersonal interactions: improved & $\begin{array}{l}\text { Discharged with ARP } 30 \text { mg, LTG } 100 \text { mg, LZP } 1 \text { mg, } \\
\text { PPL } 80 \text { mg, BZT } 0.5 \text { mg }\end{array}$ \\
\hline
\end{tabular}

ARP, aripiprazole; VPR, valproate; LZP, lorazepam; PPL, propranolol; BZT, benzatropine; LTG, lamotrigine. 
dary to seizures, rather than TSC itself, was examined. Because, about $10 \%$ of children with complex partial seizures were reported to have a schizophrenia-like psychosis. ${ }^{10)}$ However, those children displayed poor seizure control. Our patient remained seizure free for three years and her symptoms continued despite no abnormality was found on EEG. Furthermore, positive symptoms like hallucinations and delusions were associated in psychosis with seizures but negative symptoms were not. ${ }^{10)}$ In contrast, our patient exhibited negative symptoms as well as positive symptoms for substantial period of time, irrespective of the mood status.

Thirdly, an antidepressant-induced mood switch was also considered. However, even after venlafaxine discontinuation for five months, the symptoms remained. Moreover, after the initial stabilization in the absence of an antidepressant, the switch of mood stabilizer from valproate to lamotrigine sufficed the reemergence of manic symptoms. Therefore, the antidepressant cannot be a direct cause of the bipolarity.

Still, we believe that prescribing venlafaxine to TSC patients, whom might be more prone to bipolar disorder, should be done cautiously since venlafaxine was associated with more manic switches. ${ }^{11)}$

The literature about psychotic or bipolar disorder in TSC is almost non-existent. Whereas some numbers of cases were reported about psychotic symptoms, only six cases of TCS with mania were found in PubMed literature search until September 2015. ${ }^{12-17)}$

The prevalence for seizure, autism and MR are high in TSC with $85 \%,{ }^{18)} 30-50 \%{ }^{4,5)}$ and $42-64 \%{ }^{9,12)}$ respectively. Moreover, those three disorders also demonstrated high comorbidity for psychosis. ${ }^{19-21)}$ Therefore, TSC may also have an association with psychosis and warrants further investigations.

The highly reported hyperactivity in TSC $(56 \%),{ }^{9)}$ also raises the suspicion of under-diagnosed bipolarity. In TSC, ADHD is also prevalent with reported prevalence of $30-50 \%{ }^{4,6,7)}$ Considering that both ADHD and autism have high comorbidity of bipolar disorder, ${ }^{22,23)}$ TSC may also encompass high incidence of bipolar disorder. Furthermore, chromosome 16p13.3, where TSC 2 gene is located, was reported to have linkage evidence for bipolar affective disorder. ${ }^{24)}$ Therefore the risk of bipolarity should be properly assessed in TSC.

The reason for relatively less attention given to psychotic or manic symptoms in TSC may lie in part due to the fact that pediatricians or neurologists, whom TSC patients usually encounter, are not familiar in diagnosing such disorders. In addition, mistaking negative symptom of social withdrawal as a symptom of autism or impulsivity/hallucinatory behaviors as behaviors stemming from MR might have underlain for the under-estimation. Even though $90 \%$ of TSC patients display psychiatric problems in life, only $20 \%$ of those receive adequate evaluation and management. ${ }^{25)}$ Additionally to the under-diagnosis due to the overlapping symptoms, we hypothesize that the widespread use of anti-epileptics in TSC may have masked the underlying bipolarity. Considering that the bipolar disorder is not a rare disorder, there is still a chance of co-incidental occurrence of TSC and bipolarity. Still, anticonvulsants already prescribed for seizures might have a protective role against outburst of such manic episode. Therefore, additional caution should be applied when evaluating TSC patients for mood and when anti-epileptics are decided to be discontinued in in TSC.

As literatures on such conditions are scarce, so do the management options. In addition to drawing more clinical attention to TSC, we would like to share our successful treatment experience with aripiprazole and lamotrigine. Although manic symptoms were a major concern, the patient suffered most extensively from depression and psychomotor retardation. Lamotrigine was chosen adjunctively to aripiprazole, as lamotrigine was effective in the depressed phase of bipolar disorder. ${ }^{26)}$

Nevertheless, safety and tolerability actually came first before effectiveness in mood stabilizer selection. Valproate and lithium are widely used mood stabilizers. However, the patient was not tolerant to valproate and lithium may increase the risk of seizure. ${ }^{27)}$ Moreover, lithium usage may become problematic if renal complications occur later by TSC, which is the most common cause of mortality in $\mathrm{TSC}^{28)}$

Lamotrigine was chosen not only as a mood stabilizer, but also as a safe measure against possible seizure relapse in the future. In the literature, vigabatrin and topiramate were other frequently prescribed anti-epileptics in TSC. However, they are both not approved as mood stabilizers. Furthermore, vigabatrin may induce peripheral visual field defect in $25-50 \%$ of exposed patients. ${ }^{29)}$ Topiramate may worsen cognitive functions, ${ }^{30-32)}$ which may negatively impact on already disadvantaged patient's intelligence. On the other hand, lamotrigine was not associated with cognitive impairment. ${ }^{33,34)}$

The main purpose for prescribing aripiprazole was to mitigate both the psychotic and manic symptoms. Aripiprazole has partial agonistic activities at dopamine $\mathrm{D} 2$ and serotonin 5-HT1A receptors, while also acting as an an- 
tagonist at serotonin 5-HT2A receptor. This unique receptor profile of aripiprazole provides some favorable advantages over other antipsychotics in terms of extrapyramidal symptoms, sedation, hyperprolactinemia, and metabolic side effects like weight gain. ${ }^{35)}$ Thus, aripiprazole was suggested to be both safe and effective for treating pediatric patients with bipolar disorders. ${ }^{35,36)}$ Improvement of cognitive function was reported in chronic schizophrenia after switching to aripiprazole. ${ }^{37)}$ Considering the high comorbid intellectual disabilities in TSC, as demonstrated by borderline intellectual funcioning in this case, aripiprazole may have additional value in cognitive domain over other antipsychotics.

In addition to controlling psychotic or behavioral disturbances, aripiprazole can also be useful in dealing with highly prevalent depressive symptoms in TSC, as it is also indicated for adjunctive treatment for major depressive disorder.

In conclusion, aripiprazole and lamotrigine have many potential advantages in treating TSC. While lamotrigine could be a good treatment option in TSC, a combination therapy with an antipsychotic like aripiprazole might be more useful in the acute phase considering the long required build-up time of lamotrigine.

Some promising clinical trial outcomes were reported with mammalian target of rapamycin inhibitors. ${ }^{38)}$ It should also be assessed whether TSC associated neuropsychiatric disorders (TAND) could also be improved. Even without a disease-modifying treatment option, psychiatric and related behavioral problems may still be managed effectively in TSC. Delayed recognition and management of those problems put the TSC patients and their families in unnecessary suffering. Therefore, TAND should be a major clinical focus when treating TSC patients. Furthermore, whenever encountering symptoms like fluctuation of mood, delusions, sudden changes of behavior, and vegetative functions occur, bipolar/psychotic spectrum disorder should also be evaluated.

\section{Acknowledgments}

We appreciate Stephen Parsons at the British Council, Korea for correcting the writing.

\section{REFERENCES}

1. Roach ES. Diagnosis and management of neurocutaneous syndromes. Semin Neurol 1988;8:83-96.

2. Osborne JP, Fryer A, Webb D. Epidemiology of tuberous sclerosis. Ann N Y Acad Sci 1991;615:125-127.

3. Au KS, Williams AT, Gambello MJ, Northrup H. Molecular genetic basis of tuberous sclerosis complex: from bench to bedside. J Child Neurol 2004;19:699-709.
4. Leclezio L, de Vries PJ. Advances in the treatment of tuberous sclerosis complex. Curr Opin Psychiatry 2015;28:113-120.

5. Curatolo P, Napolioni V, Moavero R. Autism spectrum disorders in tuberous sclerosis: pathogenetic pathways and implications for treatment. J Child Neurol 2010;25:873-880.

6. D'Agati E, Moavero R, Cerminara C, Curatolo P. Attentiondeficit hyperactivity disorder (ADHD) and tuberous sclerosis complex. J Child Neurol 2009;24:1282-1287.

7. Muzykewicz DA, Newberry P, Danforth N, Halpern EF, Thiele EA. Psychiatric comorbid conditions in a clinic population of 241 patients with tuberous sclerosis complex. Epilepsy Behav 2007;11:506-513.

8. Prather P, de Vries PJ. Behavioral and cognitive aspects of tuberous sclerosis complex. J Child Neurol 2004;19:666-674.

9. de Vries PJ, Hunt A, Bolton PF. The psychopathologies of children and adolescents with tuberous sclerosis complex (TSC): a postal survey of UK families. Eur Child Adolesc Psychiatry 2007;16:16-24.

10. Caplan R, Arbelle S, Magharious W, Guthrie D, Komo S, Shields WD, et al. Psychopathology in pediatric complex partial and primary generalized epilepsy. Dev Med Child Neurol 1998;40:805-811.

11. Leverich GS, Altshuler LL, Frye MA, Suppes T, McElroy $\mathrm{SL}$, Keck PE Jr, et al. Risk of switch in mood polarity to hypomania or mania in patients with bipolar depression during acute and continuation trials of venlafaxine, sertraline, and bupropion as adjuncts to mood stabilizers. Am J Psychiatry 2006;163:232-239.

12. Raznahan A, Joinson C, O'Callaghan F, Osborne JP, Bolton PF. Psychopathology in tuberous sclerosis: an overview and findings in a population-based sample of adults with tuberous sclerosis. J Intellect Disabil Res 2006;50:561-569.

13. Khanna R, Borde M. Mania in a five-year-old child with tuberous sclerosis. Br J Psychiatry 1989;155:117-119.

14. Hagenah U, Coners H, Kotlarek F, Herpertz-Dahlmann B. Tuberous sclerosis and organic bipolar disorder in a 15-year-old adolescent. Z Kinder Jugendpsychiatr Psychother 1999;27:283-289.

15. Chopra VK, Cintury Y, Sinha VK. Bipolar disorder associated with tuberous sclerosis: Chance association or aetiological relationship? Indian J Psychiatry 2006;48:66-68.

16. Haq MZ, Dubey I, Khess CR, Das U, Kumar R. Bipolar disorder and tuberous sclerosis complex: is it a mere coincidence? CNS Spectr 2009;14:643-647.

17. Al-Sharbati M, Al-Zaidi R, Al-Naamani R, Al-Futaisi A, Jain R. A rare presentation of attention deficit/hyperactivity disorder: A recommendation to be more alert! Sultan Qaboos Univ Med J 2010;10:84-88.

18. Sparagana SP, Roach ES. Tuberous sclerosis complex. Curr Opin Neurol 2000;13:115-119.

19. Qin P, Xu H, Laursen TM, Vestergaard M, Mortensen PB. Risk for schizophrenia and schizophrenia-like psychosis among patients with epilepsy: population based cohort study. BMJ 2005;331:23.

20. Raja M, Azzoni A. Autistic spectrum disorders and schizophrenia in the adult psychiatric setting: diagnosis and comorbidity. Psychiatr Danub 2010;22:514-521.

21. Cooper SA, Smiley E, Morrison J, Allan L, Williamson A, Finlayson J, et al. Psychosis and adults with intellectual disabilities. Prevalence, incidence, and related factors. Soc Psychiatry Psychiatr Epidemiol 2007;42:530-536.

22. Munesue T, Ono Y, Mutoh K, Shimoda K, Nakatani H, Kikuchi M. High prevalence of bipolar disorder comorbidity in adolescents and young adults with high-functioning autism spectrum disorder: a preliminary study of 44 
outpatients. J Affect Disord 2008;111:170-175.

23. Tamam L, Karakus G, Ozpoyraz N. Comorbidity of adult attention-deficit hyperactivity disorder and bipolar disorder: prevalence and clinical correlates. Eur Arch Psychiatry Clin Neurosci 2008;258:385-393.

24. Daniels RJ, Peden JF, Lloyd C, Horsley SW, Clark K, Tufarelli C, et al. Sequence, structure and pathology of the fully annotated terminal $2 \mathrm{Mb}$ of the short arm of human chromosome 16. Hum Mol Genet 2001;10:339-352.

25. de Vries PJ, Whittemore VH, Leclezio L, Byars AW, Dunn $\mathrm{D}$, Ess KC, et al. Tuberous sclerosis associated neuropsychiatric disorders (TAND) and the TAND Checklist. Pediatr Neurol 2015;52:25-35.

26. Geddes JR, Calabrese JR, Goodwin GM. Lamotrigine for treatment of bipolar depression: independent meta-analysis and meta-regression of individual patient data from five randomised trials. Br J Psychiatry 2009;194:4-9.

27. Adityanjee, Balaraju KB, Ahuja GK. Prior neurologic illness and the syndrome of irreversible lithium-effectuated neurotoxicity (SILENT). Aust N Z J Psychiatry 1989;23: 422-424.

28. Shepherd CW, Gomez MR, Lie JT, Crowson CS. Causes of death in patients with tuberous sclerosis. Mayo Clin Proc 1991;66:792-796.

29. Willmore LJ, Abelson MB, Ben-Menachem E, Pellock JM, Shields WD. Vigabatrin: 2008 update. Epilepsia 2009;50: 163-173.

30. Tatum WO 4th, French JA, Faught E, Morris GL 3rd, Liporace
J, Kanner A, et al; PADS Investigators. Post-marketing antiepileptic drug survey. Postmarketing experience with topiramate and cognition. Epilepsia 2001;42:1134-1140.

31. Lee S, Sziklas V, Andermann F, Farnham S, Risse G, Gustafson $\mathrm{M}$, et al. The effects of adjunctive topiramate on cognitive function in patients with epilepsy. Epilepsia 2003;44:339-347.

32. Loring DW, Meador KJ. Cognitive side effects of antiepileptic drugs in children. Neurology 2004;62:872-877.

33. Bourgeois B. New dosages and formulations of AEDs for use in pediatric epilepsy. Neurology 2002;58(12 Suppl 7): $: 2-S 5$.

34. Pressler RM, Binnie CD, Coleshill SG, Chorley GA, Robinson RO. Effect of lamotrigine on cognition in children with epilepsy. Neurology 2006;66:1495-1499.

35. Kirino E. Profile of aripiprazole in the treatment of bipolar disorder in children and adolescents. Adolesc Health Med Ther 2014;5:211-221.

36. Oh J, Chang JG, Lee SB, Song DH, Cheon KA. Comparison of aripiprazole and other atypical antipsychotics for pediatric bipolar disorder: a retrospective chart review of efficacy and tolerability. Clin Psychopharmacol Neurosci 2013;11:72-79.

37. Lee JG, Lee JH, Ha EK, Kim MC, Kim YH. Switching patients with chronic schizophrenia to aripiprazole: the improvement in cognitive function. Clin Psychopharmacol Neurosci 2006;4:32-39.

38. Sampson JR. Therapeutic targeting of mTOR in tuberous sclerosis. Biochem Soc Trans 2009;37:259-264. 